\title{
Analysis of Annual Precipitation and Water Table Changes in Shahrekord Aquifer
}

\author{
Rahim Alimohammadi Nafchi* \\ Agricultural Engineering Research Department, Chaharmahal and Bakhtiari Agricultural and \\ Natural Resources Research and Education Center, AREEO, Shahrekord, Iran \\ *Corresponding author
}

\begin{tabular}{|l|}
\hline Ke y w o r d s \\
Jahanbin basin, \\
Drought, SPI, DM, \\
ADI, RAI, SWI and \\
PNI indices \\
\hline Article Info \\
\hline $\begin{array}{l}\text { Accepted: } \\
\text { 07 April } 2018 \\
\text { Available Online: } \\
\text { 10 May } 2018\end{array}$ \\
\hline
\end{tabular}

A B S T R A C T

The growth of technology has caused climate change around the world whose results are warming of the air, the occurrence of low precipitation periods, the conversion of snow into rain, and shortening of the length of snow remaining in the area. This research has analyzed Jahanbin basin and Shahrekord plain using water balance method and common indices. The results obtained using Standard Precipitation Index (SPI), Drought Magnitude (DM), Average Duration of Drought Intensity (ADI), Rainfall Anomaly Index (RAI), Standard Water Index (SWI) and Percentage of Normal Index (PNI), indices, indicated negative performance in the catchment area. Rainfall Anomaly index has risen to -4.56 , even the SWI index shows that since 2000 the pressure on groundwater resources has increased, and withdrawals have exceeded the maximum allowable and water balance of the region is negative, which will continue until 2017, and the value of this index has reached -2.226. Moreover, the analysis of the moving average chart indicates the occurrence of drought periods in previous times, yet with the proper management of consumption, people have spent those times not many challenges. But, since 2007, about a decade ago, people have consumed water regardless of collective interest (benefit), optimal water consumption, and sustainable development, which had created an unfavorable condition.

\section{Introduction}

Climate disturbances or drought is a crawling and stealthy phenomenon, and its temporal and spatial descriptions require expertise and experience and thus are not easy. It has a special severity, magnitude, and duration that can cover large areas, and when it occurs, the economic, social, political, and environmental effects will remain in the region for a long time. Drought has various types, including meteorology drought (periods when rainfall is less than normal), hydrological droughts (by measuring river discharge), and agricultural drought (soil moisture).

In Mazandaran, Karimi et al., (2010) concluded that normal and docile indices had the same trend in the stations studied, SPI, ZSI and CZI were consistent with each other two by two along having proper curve correlation, and only MCZI index had differences (Karimi et al., 2010). At the synoptic station of Mashhad, using time series and modeling 
based, Shafiee et al., (2011) analyzed Palmer's drought intensity index and concluded that in recent years, in addition to persistence, the intensity of droughts has increased (Shafiei et al., 2011). In South Khorasan Yazdi et al., (2014) with average rainfall of $200 \mathrm{~mm} /$ year, stated water use efficiency as $0.62 \mathrm{~kg}$ per cubic meter of water. They estimated the largest agricultural product trade from 2008 to 2012 in the import of rice with a volume of 7.7 million cubic meters of water and for the export of virtual volumes of 20 million cubic meters of tomato paste, potatoes, and apple. In addition, the index of water footprint in the province was 1723 cubic meters per person (Arabi Yazdi et al., 2014). Karimi et al., (2016) used RAI, SDI, SIAP and SWI indices to study drought In Qarasoo watershed in Kermanshah and concluded that the worst drought intensity was in 2007 and the longest droughts period occurred from 2007 to 2012, and hydrological droughts have been create with one to two years of delay compared to the meteorological drought (Karimi et al., 2016). In England, Fowler and Wilby (2010) concluded that precipitation change due to climate change is a global trend, and suggested that special management should implemented in the basins and indicators and parameters for climate change and meteorology across the globe should be measured and evaluated. Moreover, they suggested that by observing environmental concerns, one could prevent the growing trend of climate change (Fowler and Wilby, 2010). In the eastern province of Buenos Aires, Argentina, in relation to the effect of precipitation on groundwater levels, Silvina et al., (2012) found that the level of the underground water is a function of the value of precipitation, which rose about $97 \mathrm{~mm}$ per month in the rain seasons. Moreover, and it is easy to determine the equation between rainfall height and zone of saturation waterlevel changes. This equation can be use to manage water resources, especially underground resources (Silvina et al., 2012). Qu et al., (2016) analyzed the daily rainfall in order to investigate the changes in rainfall and its effect on runoff in the basins of the big rivers of China, based on seasonal and annual time scales. They concluded that the average annual rainfall in China grew by $1.1 \mathrm{~mm}$ per year (from 1960 to 2013). However, it has created many spatial changes, and the intensity of rainfall has increased $(\mathrm{Qu}$ et al., 2016). In a study, in Gangwon, South Korea, Jeong and Park (2017) concluded that the groundwater level is a function of the amount, time, and intensity of precipitation and with different time lags, and the thickness of the unsaturated layer is effective at this time (Jeong and Park, 2017).

\section{Materials and Methods}

This research conducted in Chaharmahal and Bakhtiari, Iran, in the geographical range of 263563 to $646525 \mathrm{~m}$, the eastern length and 9664597 to $9649749 \mathrm{~m}$, northern latitude. The study used the meteorological statistics of the synoptic station of Shahrekord, with a height of $2049 \mathrm{~m}$ above sea level, average rainfall of $319.4 \mathrm{~mm}$, relative humidity of $25 \%$, and annual evaporation rate of $1710 \mathrm{~mm}$. The climate of Shahrekord is semi-arid by De Martonne method and moderate cold with hot and dry summer by Köppen method.

Drought is a random probabilistic phenomenon, which has usually occurred at different times at Shahrekord station.

\section{Runs approach}

In this test, random features of time series examined.

Calculating the average rainfall

$p_{m}=\frac{\sum_{i=1}^{n} p_{i}}{n}$ 
Selection drought threshold: Estimated rainfall is equivalent to $80 \%$ of the average annual rainfall.

Drought duration $L_{i}$

Drought magnitude $S_{i}$

Drought intensity

$D_{i}=\frac{S_{i}}{L_{i}}(2)$

Drought severity is one of the important pillars of the drought studies in any area in determining the indicators for measuring the extent, intensity, and duration of the drought period. Drought index is actually a function of various environmental factors affecting the drought phenomenon.

\section{Standard Precipitation Index (SPI)}

The values first fitted according to the normal statistical distribution (Mckee et al., 1993).

$S P I=\frac{p_{i}-\bar{p}}{s}$

$S=\sqrt{\frac{\sum_{i=1}^{n}\left(p_{i}-\bar{p}\right)^{2}}{n-1}}$

Drought Magnitude (DM) (Mckee et al., 1995)

$D M=-\left(\sum_{i=1}^{n} S P I_{i}\right)(5)$

Average Duration of Drought Intensity (ADI)

$A D I=\frac{D M}{n}(6)$

\section{Rainfall Anomaly Index (RAI)}

If the annual rainfall to be more than average rainfall, then, The Rainfall Anomaly index will be positive (equation 7) and if to be less, the index would be negative (equation 8), (Rooy 1965 and Feites, 2005).

If $\mathrm{p} \geq R A I=3 \times(p-\bar{p}) /(m-\bar{p})(7)$

If $\mathrm{p} \leq \mathrm{p}$ RAI $=3 \times(p-\bar{p}) /(x-\bar{p})_{(8)}$

$\bar{p}$ : Long-term average precipitation

$\mathrm{m}$ : The average of ten of the highest values

$\mathrm{x}$ : The average of ten of the lowest values

Standard Water Index (SWI) (Bhuiyan 2004)

$\mathrm{SWI}=\frac{w_{i}-\bar{w}}{s}$

Wi: Groundwater level per year

$\bar{W}$ : Average groundwater level

\section{Percentage of Normal Index (PNI)}

By dividing the rainfall each year to the longterm average and multiplied in 100 (percentage).

$\mathrm{PNI}=\frac{p_{i}}{\bar{p}}(10)$

\section{Results and Discussion}

Given the changes in annual rainfall in Shahrekord station (Figure 1), we understand that drought does not belong to a particular period, but from old times, drought periods have existed in the area varying intensity and durations, and the interesting thing is that the recent drought period is much less intense than before, but its duration is longer. This issue has happened while the water scarcity has had a tremendous impact on the everyday life of the people of the region, and the region has witnessed the incidents and challenges arising from the lack of belief in the management and optimal sustainable consumption of water resources. Jahanbin Basin has 854 active deep and semi-deep 
wells with an annual harvest of 180 million cubic meters per year for many years. This is true while annual precipitation has changed dramatically. Nevertheless, the amount of water extracted from groundwater resources has increased far more.

Figures 1 and 2 are the dominant test indices and Rainfall Anomaly index, both of which indicate the occurrence of droughts in periods from the beginning (about 59 years ago), and the lack of rainfall or drought are unavoidable events (Table 1). Therefore, free from any pressure on water resources (surface or underground), exploiters and even different authorities should enforce the law with a firm belief in implementing optimal consumption and integrated and sustainable management of water resources.

The values of rainfall abnormalities in figure 2 and Table 2 indicate that droughts have existed in previous times and even more intensely (1980), but in recent years droughts have been much less (weak). But its impact on people's lives is more than past tenses.
Because we have not yet succeeded or did not want to adapt to the conditions of the region.

With a close look at figure 3, we find that even if it managed with the long-term average, $319.4 \mathrm{~mm}$ per year, the adverse condition and negative balance of the plain will, finally, lead to the compulsory migration from the area. Figure 3 shows that if we plan to use $255 \mathrm{~mm}$ per year, and take necessary measures in the watershed management and water storage, we can have a sustainable livelihood in the basin. Nevertheless, if we plan on the long-term average, the critical situation in the plain will be a serious warning, and this is not consistent with optimal and sustainable consumption in the region.

The standard annual precipitation index (Fig. 4 and Table 2 and 3) standardization of precipitation class indexing has shown relatively dry to very dry droughts in the region. This suggests that the study area is a rather dry to semi-arid region, and one must adapt to the circumstances by understanding the facts and avoid over-consumption.

Table.1 Classification of the values of SPI and RAI

\begin{tabular}{|c|c|c|}
\hline Classification & RAI (10) & SPI (14) \\
\hline Extremely wet & More than 3 & More than 2 \\
\hline Very wet & 2 to 2.99 & 1.5 to 1.99 \\
\hline Moderately wet & 1 to 1.99 & -0.99 to 0.99 \\
\hline Near normal & 0.5 to -0.99 & -0.99 to -1.49 \\
\hline Moderately dry & -1.00 to -1.99 & -1 to 1.49 \\
\hline Very dry & -2.00 to -2.99 & -1.5 to -1.99 \\
\hline Extremely dry & Less than -3 & Less than -2 \\
\hline
\end{tabular}

Table.2 Classification of PNI (World Meteorological organization, 2012)

\begin{tabular}{|c|c|c|}
\hline Drought class & Amount (percent) & Rating \\
\hline Partial & $70-80$ & 1 \\
\hline Average & $55-70$ & 2 \\
\hline Intense & $40-55$ & 3 \\
\hline Very intense & Less than 40 & 4 \\
\hline
\end{tabular}


Table.3 Part of the results obtained according to the calculated indices

\begin{tabular}{|c|c|c|c|c|c|c|}
\hline \multirow[t]{2}{*}{ Row } & \multirow[t]{2}{*}{ Year } & \multicolumn{5}{|c|}{ The results of tests and indices } \\
\hline & & SPI & PNI & RAI & SIAP & SWI \\
\hline 1 & 1959 & -1.72 & 0.508 & -3.88 & -1.72 & - \\
\hline 2 & 1960 & 0.725 & 1.20 & 1.39 & 0.725 & - \\
\hline 3 & 1965 & -0.367 & 0.865 & -0.827 & -0.366 & - \\
\hline 4 & 1970 & -1.18 & 0.661 & -2.68 & -1.18 & - \\
\hline 5 & 1975 & 0.362 & 1.10 & 0.699 & 0.362 & - \\
\hline$\overline{6}$ & 1980 & 1.145 & 1.32 & 2.21 & 1.14 & - \\
\hline 7 & 1985 & 0.554 & 1.15 & 1.07 & 0.554 & 0.573 \\
\hline 8 & 1990 & 0.181 & 1.105 & 0.349 & 0.181 & 0.779 \\
\hline 9 & 1995 & 0.575 & 1.16 & 1.11 & 0.575 & 1.05 \\
\hline 10 & 2000 & -0.960 & 0.726 & -2.16 & -0.960 & -0.409 \\
\hline 11 & 2001 & -0.843 & 0.759 & -1.90 & -0.843 & -0.834 \\
\hline 12 & 2002 & -0.471 & 0.865 & -1.06 & -0.471 & -0.565 \\
\hline 13 & 2003 & 0.281 & 1.08 & 0.542 & 0.281 & -.0666 \\
\hline 14 & 2004 & -0.449 & 0.871 & -1.01 & -0.449 & -0.769 \\
\hline 15 & 2005 & 1.53 & 1.43 & 2.95 & 1.53 & -0.458 \\
\hline 16 & 2006 & 0.610 & 1.17 & 1.17 & 0.610 & 0.498 \\
\hline 17 & 2007 & 2.28 & 1.65 & 4.41 & 2.28 & 0.519 \\
\hline 18 & 2008 & -2.03 & 0.423 & -4.56 & -2.02 & -0.254 \\
\hline 19 & 2009 & 0.085 & 1.02 & 0.165 & 0.085 & -0.769 \\
\hline 20 & 2010 & 0.564 & 1.16 & 1.08 & 0.564 & -1.03 \\
\hline 21 & 2011 & -1.17 & 0.66 & -2.63 & -1.17 & -1.35 \\
\hline 22 & 2012 & -0.174 & 0.950 & -0.393 & -0.174 & -1.65 \\
\hline 23 & 2013 & 0.368 & 1.10 & 0.709 & 0.368 & - \\
\hline 24 & 2014 & -0.038 & 0.989 & -0.086 & -0.038 & - \\
\hline 25 & 2015 & 0.529 & 1.150 & 1.021 & 0.529 & - \\
\hline 26 & 2016 & -0.566 & 0.838 & -1.27 & -0.566 & - \\
\hline
\end{tabular}

Fig.1 Entailed test diagram in Shahrekord station

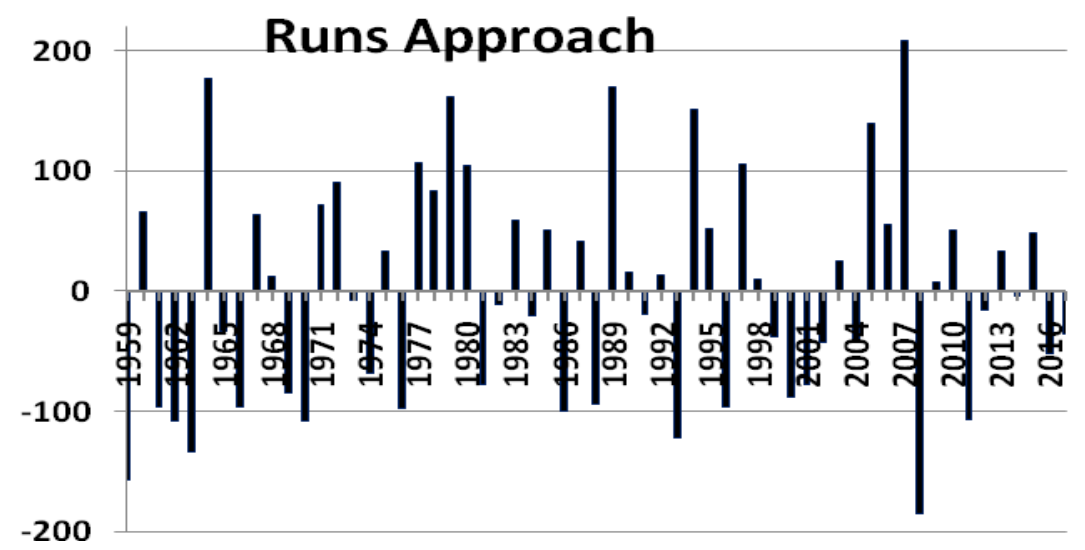


Fig.2 Long-term rainfall anomaly index (1959-2017)

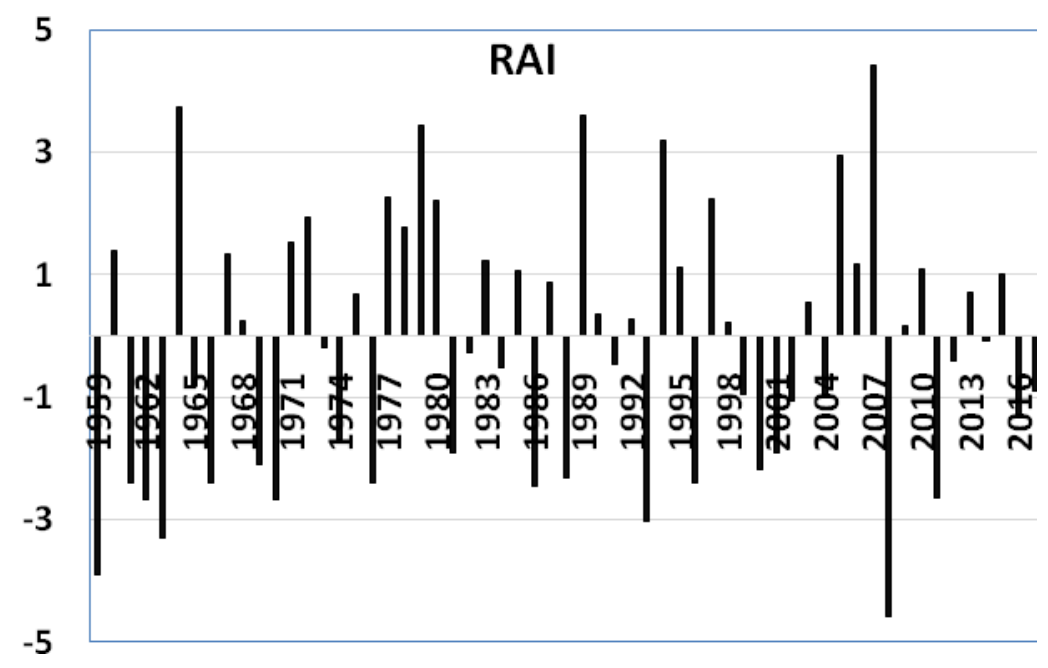

Fig.3 Average fraction cumulative chart with increasing precipitation of the adjusted average $(0.8 \mathrm{pm})$

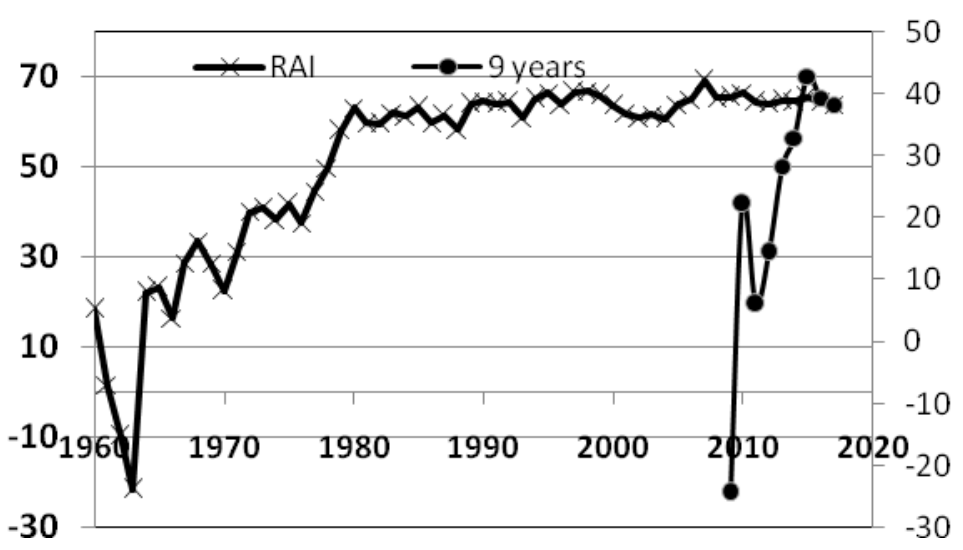

Fig.4 Annual SPI in Shahrekord station

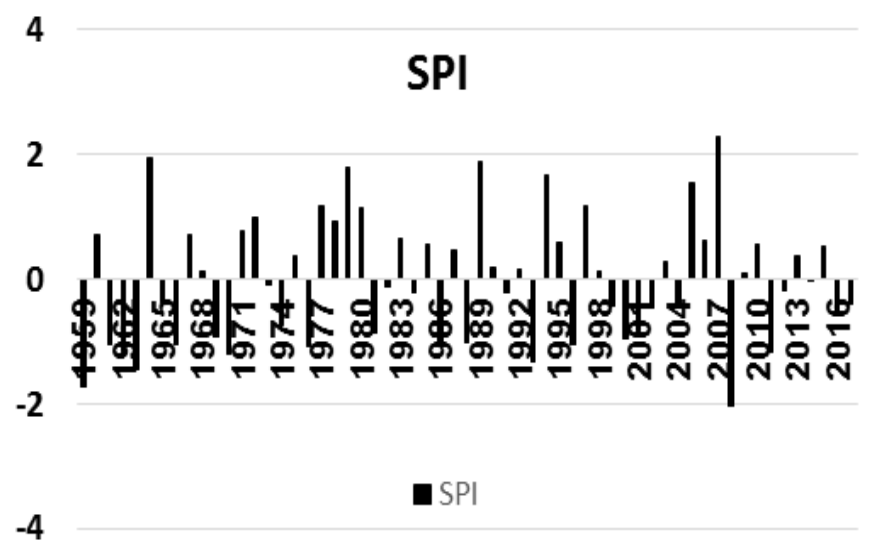


Fig.5 Changes in PNI in Shahrekord station

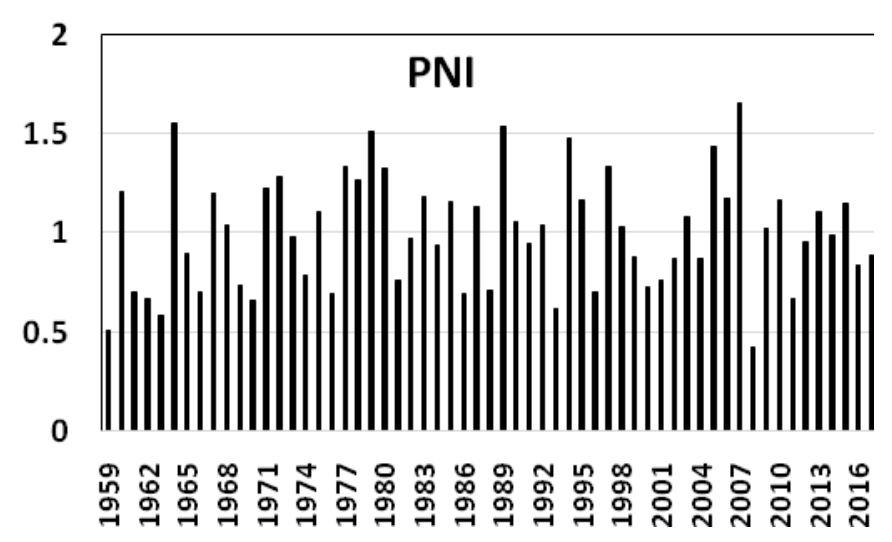

Fig.6 Changes in SWI

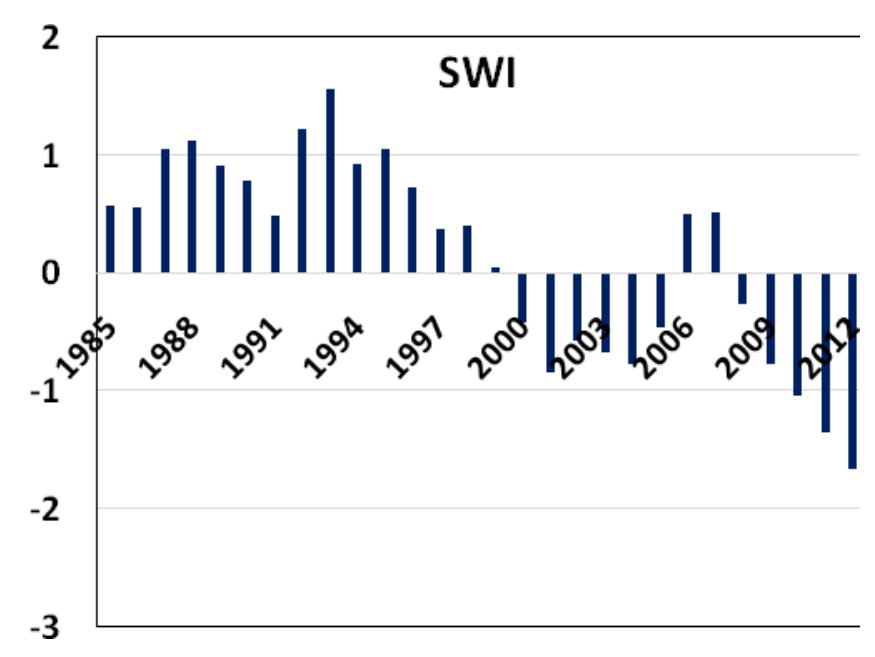

According to table 3 and figure 5 , in the last 59 years there has been only 8 years of partial drought, 9 years of average drought and 2 years of severe drought, 12 years of normal precipitation, and only 28 wet years. It is surprising now why water scarcity has caused disastrous events such as subsidence in aquifers.

SIAP index in table 3 confirmed the results of the recent indicators on the occurrence of droughts and negative water balance in the basin. Nevertheless, figure 6 of the standard groundwater level index in Shahrekord plain shows that since 1999, about 18 years ago, due to the lack of attention to annual rainfall and water withdrawal more than the capacity of the aquifer, it has had a negative balance, which has exacerbated every year in severity. In recent years, drying of springs, wells and even a large number of wells drilled, even subsidence in some places are serious warnings to the exploiters and revenant authorities.

Shahrekord plain with an area of $456 \mathrm{~km}^{2}$ and fertile soil is located in Jahanbin River basin with an area of $1260 \mathrm{~km}^{2}$, which includes $27.6 \%$ of the province's population. The only permanent river of the region (Pol Ajori River) has run out of water since 2006, and only a small flow observed in winter and 
early spring at the end of it- Kharāji strait due to the wastewater treatment plant and the outlet of several springs located on the slopes of Jahanbin Mountain. The results show that there is- there has been and will be-annual precipitation changes. Moreover, years of low rainfall or droughts have occurred alternately with different intensity and duration. This issue is not related to just a decade ago, and all indicators confirm this issue. Drought years are much less than wet and normal years, even in the last few years. The standard groundwater level indicator also showed that the status of aquifer in the plain was severely critical in the last few years due to negative water balance. Since 1999, due to the lack of surface resources, infrastructure and drying, only one surface flow of the area (Shahrkord River) in previous years and the pressure on groundwater resources and exploitation more than the aquifer capacity, each year, unfortunately, the status of the aquifer has one critical, so that SWI index has reached -2.226 in recent years. Therefore, it recommended that, due to the importance of plain and catchment area, the implementation of aquifer integration and compliance with the law have to direct towards the transfer of water from adjacent basins, so that in the future, we will not witness the movement of collective mass of people from the region.

\section{References}

Arabi Yazdi, A., Niknia N., Majidi N., and Emami H., (2014). Investigation of water security in dry climates from the point of view of the water footprint index (Case study: South Khorasan Province). Irrigation and Drainage Journal of Iran, 4(8): 735-746.

Bhuiyan, C., 2004. Various drought indices for monitoring drought condition in Aravalli terrain of India. In: Proceedings of the XXth ISPRS Conference. Int. Soc. Photogramm.
Remote Sens., Istanbul (Available at: http://www.isprs.org/istanbul2004/com m7/papers/ 243.pdf).

Fowler, H. J. and R. L. Wilby, 2010. Detecting changes in seasonal precipitation extremes using regional climate model projections: Implications for managing fluvial flood risk, Water Resources Research, 46: 1- 17.

Freitas M.A.S. 2005. Um sistema de suporte à decisão para o monitoramento de secas meteorológicas em regiões semiáridas. Rev. Tecnol. 19: 84-95.

Gibbs, W.J., Maher, J.V.: Rainfall deciles as drought indicators, Bureau of Meteorology Bulletin, 48, Melbourne, 1967.

Jeong, J. and Park, E. 2017. A shallow water table fluctuation model in response to precipitation with consideration of unsaturated gravitational flow. Water Resources Research, 53: 1- 8.

Karimi, M., Shahedi, K., Khosravi Kh. (2016). Studying meteorological and hydrological droughts using drought indices in Qarehsoo watershed. Physics of the Earth and Space, 42 (1): 170 . 159.

Karimi, V.A., Habibnejad R.M., Abarkar A. (2010). Investigating the Meteorological Drought Indices in Mazandaran Synoptic Stations. Journal of Research in Irrigation and Water Engineering, 2 (5): $25-15$.

Mckee T. B., Doesken N. J. 1993. The relationship of drought frequency and duration to time scale eight conference on applied climatology, Anahim, CA, American meteorological society, 179 188 , pp.

McKee, T.B., Doeskin, N.J., Kleist J., 1995. Drought Monitoring with Multiple Time Scales, Conference of Applied Climatology, American Meteorological Society, Boston, pp. 179-184. 
Qu, B., Aifeng, L. V., Shaofeng, J. and Zhu, W. 2016. Daily Precipitation Changes over Large River Basins in China, 1960-2013. Water (MDPI), 8 (185): 118.

ROOY, M.P., 1965. A Rainfall Anomaly Index Independent of Time and Space. Notos. 1965; 14, 43.

Shafiei, M., Ansari, H., Ghahreman, B., and Sharifi M.B. (2011). Time series modeling of drought intensity based on Palmer index. First National Conference on Drought and Climate Change, Center for Research on Water and Drought in
Agriculture and Natural Resources, May 2011, 10 pages.

Silvina C., Carretero, K. and Eduardo E. K. 2012. Relationship between precipitation and water-table fluctuation in a coastal dune aquifer: northeastern coast of the Buenos Aires province, Argentina. Hydrogeology Journal, 20: $1613-1621$.

World Meteorological organization, 2012. Guide standardized precipitation Index, user guide, weather climate water, WMO No. 1090, 25 pp.

\section{How to cite this article:}

Rahim Alimohammadi Nafchi. 2018. Analysis of Annual Precipitation and Water Table Changes in Shahrekord Aquifer. Int.J.Curr.Microbiol.App.Sci. 7(05): 560-568. doi: https://doi.org/10.20546/ijcmas.2018.705.070 